\title{
Coronary arterial anomalies in a large group of patients undergoing coronary angiography in southeast Turkey
}

\author{
S. Turkmen ${ }^{1}$, C.E. Cagliyan², F. Poyraz ${ }^{3}$, A. Sercelik¹, Y. Boduroglu1 ${ }^{1}$, R.E. Akilli², \\ M. Balli ${ }^{4}$, K. Tekin ${ }^{5}$ \\ ${ }^{1}$ Gaziantep Konukoglu University, Faculty of Medicine, Cardiology Department, Gaziantep, Turkey \\ ${ }^{2}$ Cukurova University, Faculty of Medicine, Cardiology Department, Adana, Turkey \\ ${ }^{3}$ Kırıkkale University, Faculty of Medicine, Cardiology Department, Kırıkkale, Turkey \\ ${ }^{4}$ Adiyaman University Hospital, Cardiology Department, Adiyaman, Turkey \\ ${ }^{5}$ Batman State Hospital, Cardiology Department, Batman, Turkey
}

[Received 29 December 2012; Accepted 12 February 2013]

Background: The prevalence of coronary artery anomalies (CAA) are reported between $0.6-1.3 \%$ in the literature. CAA are usually asymptomatic incidental findings, but they may deteriorate coronary circulation, cause symptoms and lead to sudden cardiac death; especially in young athletes. Since interventional procedures are increasing rapidly for treatment of coronary artery disease (CAD) in the modern era, comprehensive understanding of CAA is becoming progressively critical element in dealing with CAD.

Materials and methods: We reviewed the database of the Cardiac Catheterisation Laboratory of Sani Konukoglu University Hospital in Gaziantep, Turkey. All patients who were subjected to coronary angiography from 1998 to 2006 were included. Results: Among 53,655 coronary angiographies performed, CAA were found in 653 patients (incidence of 1.21\%); 590 (90.3\%) patients had anomalies of origin and distribution and 63 (11.7\%) had coronary fistulae. Separate origins of left anterior descending ( $L A D)$ and left circumflex ( $L C X)$ coronary artery from the left sinus of Valsalva was the most common anomaly (64.1\%). Coronary arteries branching from anomalous aortic origin was the second most common anomaly (16.5\%). Right coronary artery (RCA) originating from left sinus of Valsalva or left main coronary artery (LMCA) was observed in 55 (8.4\%) patients, LCX arising from $R C A$ or right sinus of Valsalva (RSV) was seen in 52 (7.9\%) patients and LMCA or LAD originating from RSV was seen in $14(0.2 \%)$ patients. There were 16 (2.45\%) patients with single coronary artery and $1(0.15 \%)$ patient with LMCA originating from pulmonary artery.

Conclusions: The incidence and the pattern of CAA in our patient population were similar with previous studies. Angiographic recognition of these vessels is important because of their clinical significance and importance in patients undergoing coronary angioplasty or cardiac surgery. (Folia Morphol 2013; 72; 2: 123-127)

Key words: coronary artery anomalies, coronary artery fistulae, coronary angiography

Address for correspondence: C.E. Cagliyan, MD, Cukurova University Faculty of Medicine, Department of Cardiology, 01330, Balcali, Saricam, Adana, Turkey, fax: +90 322 3386945, e-mail: cemrec76@hotmail.com 
Table 1. Incidence of coronary anomalies

\begin{tabular}{lccc}
\hline Kind of anomaly & Count $(\mathbf{n})$ & Ratio $(\%)$ & Ratio within anomalies $(\%)$ \\
\hline Anomalies of origin and distribution & 590 & 1.10 & 90.3 \\
Coronary artery fistulae & 63 & 0.11 & 9.7 \\
\hline
\end{tabular}

\section{INTRODUCTION}

Coronary arterial anomalies (CAA) are reported to occur between $0.6-1.3 \%$ [22, 24, 25]. In this modern era, where invasive treatment strategies for coronary arterial disease are increasing rapidly, comprehensive knowledge and experience about CAA are mandatory for cardiologists and surgeons dealing with invasive cardiology. The clinical importance of CAA may vary between asymptomatic harmless conditions to hazardous lesions, which may even lead to sudden cardiac death (SCD). Some CAA may cause angina, dyspnoea, arrhythmias, syncope and SCD. Autopsy series blame CAA as the second most important cause of SCD observed in young athletes younger than 35 years of age $[2,15]$.

Coronary anomalies may be classified into 2 groups according to their anatomical characteristics [9]: anomalies of origin and distribution and anomalies of termination.

The latter is also known as coronary artery fistulae (CAF). In medical literature, data about CAA are mostly based on case reports and the number of investigations performed with large series of patients is really limited. The incidence of reported coronary anomalies may vary between different races and ethnic groups. In this study, we aimed to determine the incidence and types of CAA in a large series of patients in Southeast region of Turkey.

\section{MATERIALS AND METHODS}

Our study has been carried out at Sani Konukoglu University Cardiology Department. We have retrospectively analysed 53,655 coronary angiograms performed between January 1998 to December 2006. All of the angiograms were reviewed by 2 experienced invasive cardiologists. In our clinic, we hold an "anomaly notebook", in which we record all kinds of anomalies just after the invasive procedures. Our data are derived from this archive.

It is sometimes hard to differentiate "variation" from "anomaly". In this study, we didn't considered frequently observed variations such as right coronary artery (RCA) displaying separate ostia from proximal branches and the RCA originating from unusual site within right sinus of Valsalva (RSV). Also, coronary anomalies accompanying complex congenital heart disease are not included in this paper.

\section{RESULTS}

Among 53,655 coronary angiographies performed, CAA were found in 653 (1.21\%) patients; 590 $(90.3 \%)$ patients had anomalies of origin and distribution and 63 (11.7\%) had coronary fistula (Table 1).

The most common coronary anomaly was the separate origination of circumflex (LCX) and left anterior descending (LAD) arteries from left sinus of Valsalva (LSV). There were 419 patients with this anomaly and its incidence was $0.64 \%$, which constituted $64.1 \%$ of all coronary anomalies. Coronary arteries arising from anomalous aortic origin was the second most common anomaly. There were 121 (0.22\%) patients with this anomaly. Among them, left main coronary artery (LMCA) or LAD originating from RSV was observed in 14 (0.026\%) patients and RCA from LSV or LMCA was observed in $55(0.1 \%)$ patients. LCX arising from RCA or RSV was seen in $52(0.096 \%)$ patients. Anomalous aortic origin constituted $16.5 \%$ of all coronary anomalies. There were $16(0.029 \%)$ patients with single coronary artery; 13 arising from RSV and 3 from LSV. There was no patient with any coronary artery arising from non-coronary sinus of Valsalva and in only 1 patient LMCA was arising from pulmonary artery (PA) (Table 2).

There were 63 patients with CAF $(0.11 \% ; 9.6 \%$ of all anomalies) and most of them were draining into PA (46 patients; which is $73 \%$ of all fistulae). Second common drainage site was right ventricle (11 patients; $17.5 \%$ of all fistulae) and other fistulae were draining into right atrium (6 patients; $9.5 \%$ of all fistulae).

\section{DISCUSSION}

In this retrospective study, we investigated CAA in 53,655 coronary angiograms performed in a period of 8 years. Our study is the second largest one investigating CAA.

Anomalies involving origin and distribution are the most common group of CAA. Distinct origination of LCX and LAD from LSV is the most common origin 
Table 2. Distribution of coronary anomalies

\begin{tabular}{lccc}
\hline Kind of anomaly & Count $(\mathbf{n})$ & Ratio (\%) & Ratio within anomalies (\%) \\
\hline Anomalies of origin and distribution & 590 & 1.10 & 90.3 \\
Separate origins of LAD and LCX in LSV & 419 & 0.64 & 64.1 \\
LCX from RCA or RSV & 52 & 0.096 & 0.9 \\
LMCA or LAD from RSV & 14 & 0.026 & 8.4 \\
RCA from LSV or LMCA & 55 & 0.10 & 0.15 \\
LMCA from ascending aorta & 1 & 0.002 & 4.90 \\
RCA from ascending aorta & 32 & 0.06 & 0.15 \\
Ectopic origin of LMCA from PA & 1 & 0.002 & 2.45 \\
Single coronary artery & 16 & 0.029 & 1.99 \\
Origin of the LAD and LCX from RCA & 13 & 0.024 & 14.70 \\
Origin of the RCA from the LMCA & 3 & 0.006 & 9.6 \\
Coronary artery fistulae & 63 & 0.11 & 5.5 \\
LAD-PA fistula & 36 & 0.07 & 1.5 \\
LCX-PA fistula & 10 & 0.018 & 0.7 \\
Conus branch-RV fistula & 5 & 0.009 & 0.15 \\
RCA-RV fistula & 1 & 0.002 & 0.7 \\
LCX-RV fistula & 5 & 0.009 & 0.9 \\
RCA-RA fistula & 6 & 0.011 & 0.7 \\
\hline
\end{tabular}

LAD — left anterior descending; LCX — left circumflex; LSV — left sinus of Valsalva; LMCA — left main coronary artery; PA — pulmonary artery; PDA — posterior descending artery; RA — right atrium; RCA — right coronary artery; RSV — right sinus of Valsalva; RV — right ventricle

anomaly [24]. Although it is accepted as a benign anomaly, it is important to become aware of separate ostia of LAD and LCX. The orifices of both arteries are usually narrower than LMCA orifice. When percutaneous coronary intervention is planned, standard guiding catheters may induce coronary spasm and severe ostial obstruction. Smaller sized, side haled guiding catheters would be more appropriate in patients with this anomaly. The separate ostia are usually best visualised in the left anterior oblique caudal and left lateral projections.

The most frequent clinically significant CAA is the anomalous aortic origin of coronary arteries. Origination of the coronary artery from contralateral sinus of Valsalva carries the highest risk. LCX branching from RCA or RSV via separate ostia is the most frequent type; which is observed between $0.17-0.37 \%$ [7, 24, 25]. When present, LCX travels retroaortically in the atrioventricular groove and the anomaly is considered benign [18]. In the present study, total incidence of this anomaly was $0.09 \%$; lower than other studies. On the other hand, branching of RCA from LMCA or LSV was $0.10 \%$ in our study; which was reported as $0.085-0.09 \%$ in 2 studies from Turkey $[1,7]$. In contrast to benign prognosis of LCX from RCA/RSV, origination of RCA from LMCA/LAD may cause to angina pectoris, ventricular tachycardia or SCD since it may pass between great vessels [10]. Nevertheless, the most serious distribution anomaly leading to symptoms and SCD is the origination of LMCA from RSV [21]. Its incidence varies between $0.03-0.12 \%$ and clinical course is associated with the route LMCA follows in the interventricular sulcus. There are 4 routes described:

- Septal route: It is the most common course where LMCA follows an intramyocardial route beneath the right ventricular infundibulum till it reaches to interventricular groove at midseptum. Septal branches usually arise from LMCA. This form is usually benign, if obstructive coronary artery disease doesn't coexist. Angiographic landmark of this anomaly is an elliptical shape bordered inferiorly by LMCA and superiorly by LCX, resembling an eye at right anterior oblique projection.

- Anterior route: LMCA follows a route anterior to the PA, crosses right ventricular free wall and reaches epicardium at midseptum. So, the initial portion of LCX courses through aorta. In right 
anterior oblique view LCX together with LMCA forms an eye shape at the left border of aorta. In contrast to septal course, septal branches originating from LMCA are unusual in this form. This form is accepted as a benign anomaly, too.

- Retroaortic route: LMCA forms a caudo-posterior loop at posterior of the aorta and travels through its normal position, where it gives LAD and LCX. Angiographic landmark is a 'posterior dot' seen posterior of the aorta at right anterior oblique view. This form is also accepted as a benign anomaly.

- Interatrial route: It is potentially the most serious form in which LMCA follows a route between PA and aorta to reach its normal position. Angiographically it is diagnosed by an anterior dot formed by LMCA at right anterior oblique ventriculography located at the anterior left border of the aorta. Patients with this form of LMCA anomaly have complaints of chest discomfort and may suffer from premature cardiac death $[2,21]$. Compression of LMCA leading to ischaemia, angina pectoris, arrhythmias and SCD may occur during exercise and other situations leading to pressure increase in aorta and the pulmonary trunk $[8,21]$. Anomalous left coronary artery originating from the PA, which is also known as Bland-White-Garland syndrome in infancy, is present in 1/30.000-300.000 live births [4, 12]. LMCA may originate from any part of the PA, but left branch is the most common site [23]. It is usually an isolated anomaly, but may accompany congenital heart diseases like ventricular septal defect, atrioventricular cushion defect, tetratology of Fallot and truncus arteriosus [19]. Prognosis is highly dependent on coronary collateral circulation and the mortality is extremely high reaching to $90 \%$ during the first year of life [16]. The patients reaching to adulthood are lucky owing to well-developed coronary collateral vessels, but still there is ischaemic damage on the left ventricle; especially affecting the papillary muscles. Although these patients are quite asymptomatic, they carry a high SCD risk reaching to $90 \%$ at average 35 year-old age [5]. Since we reviewed a crowded population, we had a 53 year-old patient whose LMCA was originating from left PA (Figs. 1, 2). He had angina on exertion. His surveillance until that age was due to well-developed collateral flow from RCA. He was offered surgical correction; but he refused surgical intervention.

CAF are rare congenital anomalies [6]. The incidence is around $0.002 \%$ in the general population and

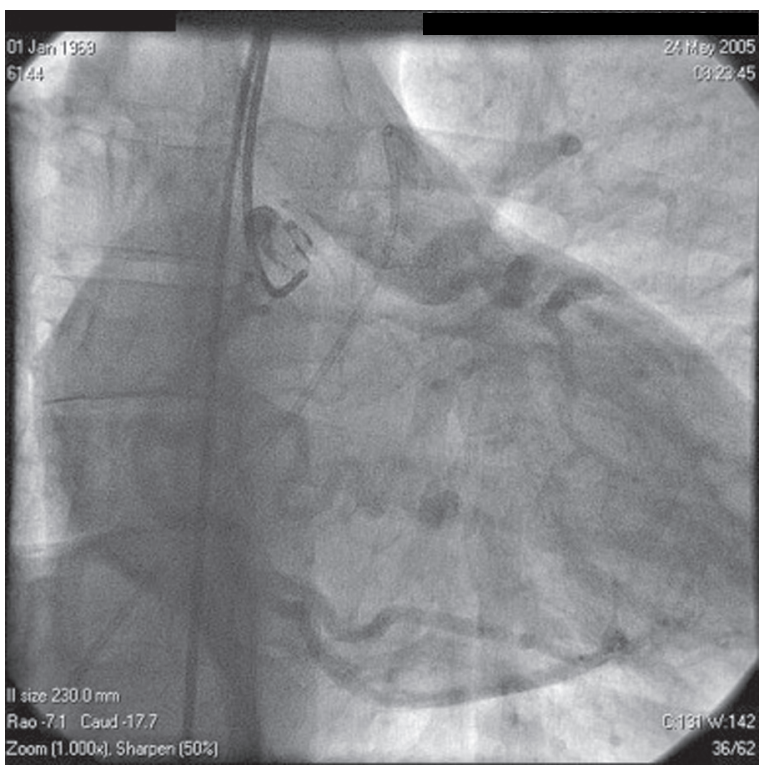

Figure 1. Right anterior oblique caudal projection shows filling of left main coronary artery (LMCA) originating from pulmonary artery via right coronary artery collaterals. In this view, pig-tail catheter is located at pulmonary artery to ascertain pulmonary origin of LMCA.

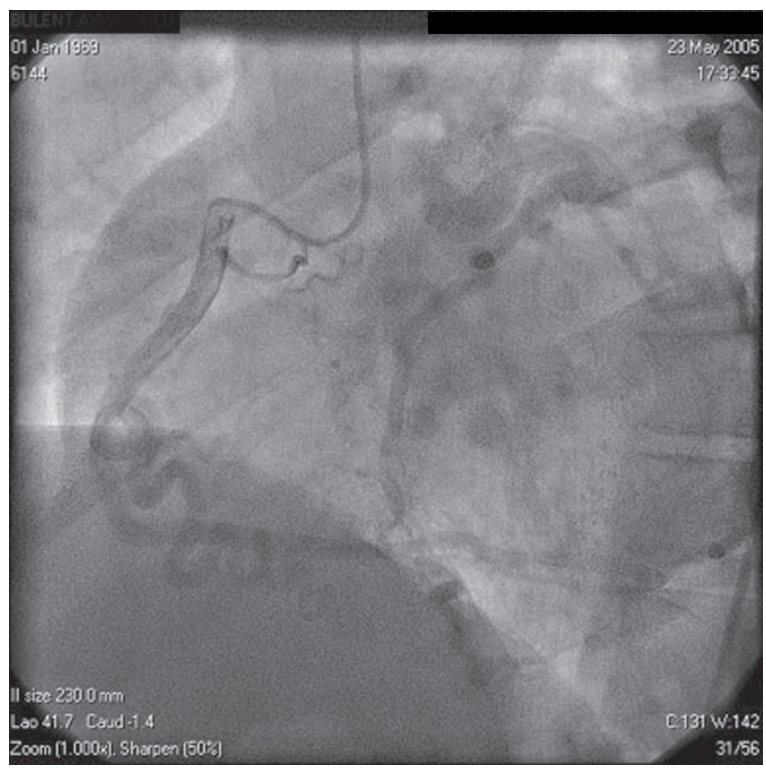

Figure 2. Very well-developed coronary collaterals from right coronary artery filling entire left circulation.

$0.3 \%$ to $0.4 \%$ in patients with congenital heart defects $[3,13]$. The CAF incidence in our study was $0.11 \%$ among patients undergoing diagnostic coronary angiography. CAF consist of a communication between a coronary artery and a cardiac chamber or a great vessel. In CAF, blood diverting from the high resistance myocardial capillary bed into the low resistance fistula produce ischaemia and coronary steal phenomenon 
[11]. The most common type of fistula is the coronary to PA type and usually arises from LAD or RCA [20]. Early phase CAF is generally not symptomatic, but later on it can cause important coronary morbidity and mortality leading to angina, syncope, congestive heart failure, myocardial infarction, and sudden death [14]. Treatment should be individualised like other types of left to right shunts and surgical and percutaneous treatments planned depending on the magnitude of the shunt, symptoms and left ventricular function [17].

Our study is the second largest study investigating CAA in patients undergoing coronary angiography. Nevertheless, data obtained by this kind of studies, the ones evaluating coronary angiograms, are not adequate for reflecting the magnitude of the problem. For more precise results, data obtained from these studies should be assessed in conjunction with necropsy series.

\section{CONCLUSIONS}

CAA are encountered more often in daily practice of high-volume centres. The incidence of anomalies may vary between different populations. The physicians dealing with adult cardiac pathologies should be familiar with these anomalies as special attention is mandatory, especially when surgery or interventional therapies are required.

\section{REFERENCES}

1. Ayalp R, Mavi A, Sercelik A, Batyraliev T, Gumusburun E (2002) Frequency in the anomalous origin of the right coronary artery with angiography in a Turkish population. Int J Cardiol, 82: 253-257.

2. Burke AP, Farb A, Virmani R, Goodin J, Smialek JE (1991) Sports-related and non-sports-related sudden cardiac death in young adults. Am Heart J, 121 (2 Part 1): 568-575.

3. Cherif A, Farhati A, Fajraoui M, Boussaada R, Hmam M, Ezzar T, Mourali S, Mechmeche R (2003) Coronary-pulmonary arterial fistula in the adult: report of 6 cases and review of the literature. Tunis Med, 81: 595-599.

4. Cowles RA, Berdon WE (2007) Bland-White-Garland syndrome of anomalous left coronary artery arising from the pulmonary artery (ALCAPA): a historical review. Pediatr Radiol, 37: 890-895.

5. Fernandes ED, Kadivar H, Hallman GL, Reul GJ, Ott DA, Cooley DA (1992) Congenital malformations of the coronary arteries: the Texas Heart Institute experience. Ann Thorac Surg, 54: 732-740.

6. Frommelt PC, Frommelt MA (2004) Congenital coronary artery anomalies. Pediatr Clin North Am, 51: 1273-1288.

7. Gol MK, Ozatik MA, Kunt A, Iscan Z, Yavas S, Soylu M, Korkmaz S, Tasdemir O (2002) Coronary artery anomalies in adult patients. Med Sci Monit, 8: CR636-CR641.

8. Isner JM, Shen EM, Martin ET, Fortin RV (1984) Sudden unexpected death as a result of anomalous origin of the right coronary artery from the left sinus of Valsalva. Am J Med, 76: 155-158.
9. Kardos A, Babai L, Rudas L, Gaal T, Horvath T, Talosi L, Toth K, Sarvary L, Szasz K (1997) Epidemiology of congenital coronary artery anomalies: a coronary arteriography study on a central European population. Cathet Cardiovasc Diagn, 42: 270-275.

10. Kragel AH, Roberts WC (1988) Anomalous origin of either the right or left main coronary artery from the aorta with subsequent coursing between aorta and pulmonary trunk: analysis of 32 necropsy cases. Am J Cardiol, 62 (10 Part 1): 771-777.

11. Levin DC, Fellows KE, Abrams HL (1978) Hemodynamically significant primary anomalies of the coronary arteries. Angiographic aspects. Circulation, 58: 25-34.

12. Malec E, Zajac A, Mikuta M (2001) Surgical repair of anomalous origin of the coronary artery from the pulmonary artery in children. Cardiovasc Surg, 9: 292-298.

13. Maleszka A, Kleikamp G, Minami K, Peterschroder A, Korfer R (2005) Giant coronary arteriovenous fistula. A case report and review of the literature. Z Kardiol, 94: 38-43.

14. Mangukia CV (2012) Coronary artery fistula. Ann Thorac Surg, 93: 2084-2092.

15. Maron BJ, Carney KP, Lever HM, Lewis JF, Barac I, Casey SA, Sherrid MV (2003) Relationship of race to sudden cardiac death in competitive athletes with hypertrophic cardiomyopathy. J Am Coll Cardiol, 41: 974-980.

16. Moodie DS, Fyfe D, Gill CC, Cook SA, Lytle BW, Taylor PC, Fitzgerald R, Sheldon WC (1983) Anomalous origin of the left coronary artery from the pulmonary artery (Bland-White-Garland syndrome) in adult patients: long-term follow-up after surgery. Am Heart J, 106: 381-388.

17. Reul RM, Cooley DA, Hallman GL, Reul GJ (2002) Surgical treatment of coronary artery anomalies: report of a 37-1/2year experience at the Texas Heart Institute. Tex Heart Inst J, 29: 299-307.

18. Sohrabi B, Habibzadeh A, Abbasov E (2012) The incidence and pattern of coronary artery anomalies in the north-west of iran: a coronary arteriographic study. Korean Circ J, 42: 753-760.

19. Takahashi $M$ (2010) Cardiac ischemia in pediatric patients. Pediatr Clin North Am, 57: 1261-1280.

20. Taleb MM, Sheikh MA, Cooper CJ, Tinkel JL (2012) Multiple coronary to pulmonary artery fistulas: a case report and review of the literature. Cardiovasc Interv Ther, 27: 127-130.

21. Taylor AJ, Rogan KM, Virmani R (1992) Sudden cardiac death associated with isolated congenital coronary artery anomalies. J Am Coll Cardiol, 20: 640-647.

22. Topaz O, DeMarchena EJ, Perin E, Sommer LS, Mallon SM, Chahine RA (1992) Anomalous coronary arteries: angiographic findings in 80 patients. Int J Cardiol, 34: 129-138.

23. Wesselhoeft H, Fawcett JS, Johnson AL (1968) Anomalous origin of the left coronary artery from the pulmonary trunk. Its clinical spectrum, pathology, and pathophysiology, based on a review of 140 cases with seven further cases. Circulation, 38: 403-425.

24. Yamanaka O, Hobbs RE (1990) Coronary artery anomalies in 126,595 patients undergoing coronary arteriography. Cathet Cardiovasc Diagn, 21: 28-40.

25. Yildiz A, Okcun B, Peker T, Arslan C, Olcay A, Bulent Vatan M (2010) Prevalence of coronary artery anomalies in 12,457 adult patients who underwent coronary angiography. Clin Cardiol, 33: E60-E64. 